\title{
The Impact of Socio-Demographic Factors on Domestic Tourism Consumption Expenditure in Ghana
}

\author{
Ebenezer Kojo Ocran ${ }^{1 *}$, Professor O. A. Adebanji² , Dr. Solomon Sarpong ${ }^{3}$ \\ 1. Ebenezer Kojo Ocran, Ghana Statistical Service, Accra, Ghana \\ 2. Professor O. A. Adebanji, Kwame Nkrumah University of Science and Technology, Kumasi, Ghana. \\ 3. Dr. Solomon Sarpong, University for Development Studies, Navrongo Campus, Navrongo, Tamale,
}

Ghana

\begin{abstract}
This study applies quantile regression approach to analyse socio-demographic factors that affect domestic tourism consumption expenditure in Ghana. The approach uses household domestic tourism expenditure as a response variable. The internet access of the household, whether a household owns a mobile phone, and /or at least one car or not are represented as proxies for information and transport accessibility, respectively. Other variables included to constrain household domestic travel budgets are yearly household income and household loan. The rest are demographic characteristics such as age and educational level of household heads. The empirical results show that relatively older and well educated household heads with higher earnings are prepared and willing to expend more on domestic tourism in Ghana. The results further show that, in Ghana, household loans are one of the major constraints of domestic tourism spending for medium and heavy spenders, but positively and significantly influence light domestic tourism expenditure households. Internet access, ownership of a car and mobile phone have no relation with the amount of money spent on domestic tourism in Ghana.
\end{abstract}

Keywords: domestic tourism, quantile regression, tourism consumption expenditure, socio-demographic variables, same-day visitors and overnight tourists.

DOI: $10.7176 / \mathrm{JTHS} / 41-05$

Publication date:May $31^{\text {st }} 2019$

\section{Introduction}

The analysis of domestic visitors' expenditure behaviour to destinations in Ghana has become increasingly important for tourism administrators, policy makers, suppliers, marketers and analysts. To understand the sociodemographic factors that influence visitors spending behaviour may lead to proper planning, better marketing and sales management as well as enhancement of opportunities in the domestic tourism industry. Regarding domestic tourism in Ghana, there is lack of data production and analysis. There is neglect for the study of domestic tourism market in terms of products and services. It is therefore imperative to focus on analysing the spending behaviour of domestic visitors whose activities have not been investigated to comprehend the association between socio-demographic factors and domestic visitors' expenditure in Ghana. Domestic tourism demand is the quantity of tourism goods or services which visitors/tourists are willing and able to purchase under a given set of conditions for a given time period (Song et al, 2000).

This paper uses quantile regression approach to analyse socio-demographic factors that affect domestic tourism consumption in Ghana. The approach uses household domestic tourism expenditure as a response variable. Apart from economic factors such as income and tourism prices which are key determinants of tourism consumption, some non-economic factors (socio-demographic factors) are considered to be contributors to domestic tourism consumption. These include age of a household head, educational level of a household head, annual income of a household, household loan, access to internet, ownership of a car and ownership of a mobile phone.

One major concern is expressed in terms of tourism economics, for example, the distributional consequences of household expenditure on tourism are of much concern to the tourism industry practitioners and policy makers, especially, in the area of policy development, formulation, discussion, implementation and evaluation. The model allows the entire conditional distribution of the response variable (expenditure) to be related to the independent variables (age, education, income, household loan, access to internet, ownership of a car and ownership of a mobile phone) to provide a richer description of functional changes than is likely to focus on just the mean (Koenker \& Bassett, 1982 \& Machado, 1999). The results are to provide useful information for governments, policy makers, travel industry operators, hotels and similar establishments, visitor attractions, internet operators and others for the management of the domestic tourism industry in Ghana. The study is to 
develop precise and well-detailed information from the domestic tourism expenditure equation in all the different levels of spending groups such as light spenders, medium spenders and heavy spenders. The main objective of the study is to investigate the association between socio-demographic variables and domestic tourism expenditure distribution.

The study assesses whether the seven indicators can influence domestic tourism demand in Ghana. Based on the literature, the following assumptions are made: i. the older the household head the likelihood that he will travel to increase in the demand for domestic tourism; ii. the higher the level of education of household head the higher the income to propel him or her to travel within the country to increase domestic tourism participation; iii. the higher the income of the household the higher the propensity for individual members to travel for tourism purposes; iv. where a household obtains a loan makes it possible for the members to engage in domestic tourism activities; v. access to internet makes it easier for visitors access to tourism information, where they can easily visit in terms of destinations; vi. possession of a means of transport by the household will make travelling easy; and, vii. ownership of a mobile phone will provide information on travel decisions and planning to encourage households to travel as domestic visitors.

\section{Literature Review}

Regarding this section, selected studies on the applications of quantile regression have been reviewed. The application of quantile regression techniques has greatly increased in recent times. For instance, labour economics has been one of the most popular fields for application by Fitzenberger (2001), but attention has been almost exclusively devoted to the study of wage equations. However, the application of the technique on tourism economics is now gaining momentum. The studies on visitor expenditure behaviour by Hung, Shang and Wang (2011), Salgado-Barandela, Baraja and Sanchez-Fernandez (2018) and Marrocu, Paci and Zara (2015) conclude that economic and socio-demographic variables as well as characteristics that relate to travel are the most repeatedly used in researches on expenditure determinants. With respect to economic factors, these authors expound that income is one of the most important and frequently utilized determinants in these studies.

The studies on visitor expenditure behaviour by Hung, Shang and Wang (2011), Salgado-Barandela et al (2018) analyse the determinants of attendee's tourism spending at professional basketball matches played in the 2012/2013 season. The results indicate that individual expenditure is highly influenced by the attendees' origin, the time the match commences, price of admission and the sporting level of the rival team.

Fitzenberger (2014) discusses that, of late, quantile regression technique is progressively used in applied econometric research. The technique allows the estimation of the differential effects of independent variables along the conditional distribution of the response variable. For instance, the wage effect of education or training may vary between low-wage and high-wage individuals.

Hung et al (2011) apply quantile regression technique to analyse the determinants of household domestic travel expenditure using travel expenditure as a response variable. The study uses socio-demographic variables as explanatory variables. The predictors are household head's age; educational level of household head; income per year of the household; household loan; access to internet; and car ownership. The results reveal that older and well educated household heads with higher income are prepared to spend more on domestic tourism in Taiwan. Households with light tourism expenditure are more likely to be affected by home loan expenditures. The results further show that the use of internet and car ownership have strong relationship with domestic tourism expenditure.

Hung et al (2012) discuss household tourism spending behaviour which applies the quantile regression approach. The study uses a percentage of tourism expenditure as the response variable. The results show that internet access and car ownership play significant roles of increasing domestic tourism expenditure in Taiwan, while household loans are one of the major constraints of tourism spending of light spenders.

Marrocu, Paci and Zara (2015) assess the effect of the main determinants of tourist expenditure by applying both linear and quantile regression models to individual micro data collected in 2012. The study finds that, in addition to income and foreign nationality, tourist expenditure is crucially driven by trip-related and psychographic characteristics. 
Moufakkir et al apply the method of volume separation to casino tourists, profile them, detect ways to mark heavy spenders and examine whether volume separation is a viable separation approach to gaming market. The study shows that a sample of visitors to two commercial casinos is divided into light, medium and heavy spenders based on spending per person per day, not including gambling. The findings indicate that a large number of heavy-spending tourists are not interested in gaming, but interested in the destination's other tourism products.

Koenker (2015) states that quantile regression is a developing body of statistical methods to estimate and draw conclusions about functions of conditional quantile. There is an application of these methods in the R language in the package, quantreg.

Sotiriadis and Varvaressos (2014) analyse the understanding of developing leisure tourism in Greece so as to have some important lessons for other tourism destinations. The study uses the technique of strategic analysis. This technique demonstrates the importance of tourism as an important economic activity and assesses the recent situation and structural problems of Greece as a destination. The result shows that Greek tourism could do better if there was a suitable tourism planning and reliable policy. Its main focus must be the sustainable development of destination.

Koenker et al (2001) point out that the traditional method of regression may turn out to be a misleading results and quantile regression is a useful procedure to overcome these problems.

Marrocu et al (2015) evaluate the effect of the main factors of tourist expenditure by using both linear and quantile regression models to individual micro data collected in 2012. The study finds that, in addition to income and foreign nationality, tourist expenditure is favourably driven by trip-related and psychographic features. The results further indicate that greater positive effects are found for heavy spenders while group size and number of visited sites add to shrinking the level of expenditure for light spender tourists.

Koenker and Basset (1978) introduced and developed the quantile regression to model the relationship between explanatory and response variables for different quantiles of the response variable.

Thrane (2014) gives practical advice on how to improve the modelling of micro-level tourism expenditure in future. Three key issues are discussed here: the choice of explanatory variables; the choice of functional form; and the choice of estimation technique.

$\mathrm{Ng}$ et al (2009) find out that visitors who repeat their visits plan to expend more in Hawaii than first time visitors. Using quantile regression approach, different spending behaviour across the whole spectrum of the tourist population is observed, from the spenders through the moderate spenders to frugal spenders.

According to Fitzenberger (2012), quantile regression is progressively used in applied econometric research. This approach permits one to estimate the effects of independent variables along the conditional distribution of the dependent variable.

Fitzenberger et al (2005) discuss quantile regression technique for duration analysis, which allows for an easy measurement of the functional relationship and of the error distribution. The study also discusses how hazard rates are estimated using quantile regression techniques. Fitzenberger (2013) discusses the linear quantile regression technique: Distance function, asymptotic distribution, properties of the estimator, and interpretation as Method-of-Moments Estimator.

Fitzenberger et al (2010) investigate the rise in wage differential, the decrease in collective bargaining, and the development of the gender wage gap in West Germany from 2001 to 2006. The results show that wage differential is strongly increasing; determined not only by rise in real wage increases at the top of the wage distribution but also by real wage decreases beneath the median.

\section{Research Methodology}

This section introduces the foundation of the methodology used in this article, and to outline and explain the research methods being utilised to meet the aims outlined in this article. 


\subsection{Data Collection}

The primary data gathered in 2012, 2013 and 2014 on domestic tourism included groups of tourism goods and services such as accommodation, food and drinks, transport, recreation, culture and sporting activities, shopping/non-consumables and other services. Data on some socio-demographic variables such as age, educational level, marital status, households' income for a year were collected. Other variables collected included owning a car, owning a mobile phone, having access to internet and contracting a loan.

\subsection{Data Analysis}

Manual editing was performed on all the questionnaires received from the field by data editor to check for the completeness and accuracy of the data. To reduce the errors, consistency checks of the data were carried out. The data was captured using the Census and Survey Processing System (CSPro). To analyse the association between domestic visitor consumption expenditure as response variable, the age of a household head, educational level of the household, income of household for a year, household loan, access of internet of the household, household ownership of a car, and mobile phone ownership of the household head or any member of the household are the explanatory variables.

\subsection{The Quantile Regression Model}

Definition: the $\theta$ - quantile of a random variable $\mathrm{Z}$ per cumulative distribution function (CDF), $F(z)=P(Z \leq z)$ is the minimum (三 infinum) value $q \theta$ for which

$$
q \theta=F^{-1}(\theta)=\inf \{z: F(z) \geq \theta\} \text {, where } \theta \in(0,1) .
$$

Thus, the quantile regression estimator, $\theta-$ quantile, of a sample $\left\{Z_{1}, \ldots, Z_{n}\right\}$, could be found as the solution to the following minimization problem:

$$
\hat{q}_{\theta}=\operatorname{argmin}(z) \sum_{i=1}^{n} \rho_{\theta}\left(Z_{i}-M\right)=\sum_{i=1}^{n}\left[\theta \cdot I\left(Z_{i}>M\right)+(1-\theta) \cdot I\left(Z_{i}<M\right)\right]\left|Z_{i}-M\right|
$$

The "check function, $\rho_{\theta}$," is dependent on the absolute deviation of residual $\left|Z_{i}-M\right|$ which is weighted by $\theta$ if positive and by $(1-\theta)$ if negative. When $\theta=0.5$ (median) we weight positive and negative residuals equally, which means that the sum of absolute deviations is minimized (Least Absolute Deviation - LAD). This minimization is formulated by a linear programming which means that the computation is straightforward (Fitzenberger, 2014).

A linear quantile regression denotes the conditional $\theta-$ quantile $\mathrm{q}_{\theta}\left(\mathrm{Y}_{i} \mid \mathrm{Z}_{2 i}, \ldots, \mathrm{Z}_{k i}\right)$ of $\mathrm{Y}_{i}$ as a linear function of regressors $\mathrm{Z}_{2 i}, \ldots, \mathrm{Z}_{k i}$.

The linear regression model:

$\mathrm{Y}_{i}=\beta_{\theta, 1}+\beta_{\theta, 2} \mathrm{Z}_{2 i}+\ldots+\beta_{\theta, k} \mathrm{Z}_{k i}+\varepsilon_{i}^{\theta}=z_{i}^{\prime} \beta_{\theta}+\varepsilon_{i}^{\theta}$

Where $\mathrm{Z}_{j i}$ observation $i$ for regressor $\mathrm{j}=2, \ldots, \mathrm{k} ; \mathrm{i}=1, \ldots, \mathrm{n}$.

$\mathrm{q}_{\theta}\left(\varepsilon_{i}^{\theta} \mid z_{i}\right)=0$, that is, the conditional quantile of the error term is equal to zero.

and $\varepsilon_{i}^{\theta}=\mathrm{Y}_{i}-z_{i}^{\prime} \beta_{\theta}$, continuously (i.i.d) random variable (conditional on $z_{i}$ ).

$\beta_{\theta}$ refers to the marginal or unit change in the $\theta$ th quantile owing to marginal or unit change in $\mathrm{Z}$; and it is the quantile coefficient that is based on $\theta$.

Estimator for $\beta_{\theta}=\left(\beta_{\theta, 1}, \ldots, \beta_{\theta, k}\right)^{\prime}$ :

$\hat{\beta}_{\theta}=\operatorname{argmin}\left(\beta_{i}, \ldots, \beta_{k}\right) \sum_{i=1}^{n} \rho_{\theta}\left(Y_{i}-z_{i}^{\prime} \beta_{\theta}\right)=\sum_{i=1}^{n}\left[\theta \cdot I\left(Y_{i}>z_{i}^{\prime} \beta_{\theta}\right)+(1-\theta) . I\left(Y_{i}<z_{i}^{\prime} \beta_{\theta}\right)\right] .\left|Y_{i}-z_{i}^{\prime} \beta_{\theta}\right|$, with $z_{i}=\left(Z_{2 i}, \ldots, Z_{k i}\right)^{\prime}$

(Fitzenberger, 2014)

3.4 Definitions of Explanatory Variables

The table below describes the explanatory variables used during the data collection exercise and analysis. 
Table 1: Definitions of explanatory variables

\begin{tabular}{|l|l|l|}
\hline Variable & Variable symbol & Description \\
\hline Age & AGE & Age of the household head \\
\hline Educational level & EDU & Educational level of the household head \\
\hline Income & INCOME & Income of the household for a year \\
\hline Loan & LOAN & Household loan $($ yes $=1$, no $=2$ ) \\
\hline Internet access & NET & Household access to internet facility (yes=1, no=2) \\
\hline Car ownership & CAR & Household car ownership (yes $=1$, no $=2)$ \\
\hline Mobile phone ownership & MOB & Mobile phone ownership $($ yes $=1$, no $=2)$ \\
\hline
\end{tabular}

\subsection{Data and Variables}

In this study, regression analyses are performed at seven different quantiles of domestic tourism expenditure distribution (i.e. $5^{\text {th }}, 10^{\text {th }}, 25^{\text {th }}, 5^{\text {th }}, 75^{\text {th }}, 90^{\text {th }}$ and $95^{\text {th }}$ percentiles) of the response variable, in other words, analysing the data set via quantile regression, using the $\theta^{\text {th }}$ quantiles $\theta \in(0.05,0.1,0.25,0.5,0.75,0.90$ and $0.95)$.

$$
\begin{aligned}
& \text { The model is characterised as follows: } \\
& Q_{\theta}\left[\theta\left[A G E_{i} \mathrm{EDU}_{\mathrm{i}}, I N C_{i}, L O A N_{i}, N E T_{i}, \mathrm{CAR}_{\mathrm{i}}, M O B_{i}\right]=\beta_{\theta}+\beta_{1 \theta} A G E_{i}+\beta_{2 \theta} E D U_{i}+\beta_{3 \theta} I N C_{i}+\right. \\
& \beta_{4 \theta} \operatorname{LOAN}_{\mathrm{i}}+\beta_{5 \theta} N E T_{i}+\beta_{6 \theta} C_{i}+\beta_{7 \theta} M O B_{i}+\varepsilon_{i}
\end{aligned}
$$

(4.6) (Hung et al, 2011)

The median regression is obtained by setting $\theta=0.5$. The remaining quantiles of the conditional distribution could be got through variation of $\theta$. To observe the relationship of the chosen independent variables across the conditional domestic tourism expenditure distribution, the model will be estimated at the 5 th, $10^{\text {th }}, 25^{\text {th }}, 50^{\text {th }}, 75^{\text {th }}$, $85^{\text {th }}$ and 95 th quantiles. The numerical variables are EXPENDITURE, AGE and INCOME which are transformed in natural logarithms.

In $E X P=\beta_{0}^{\text {sarithms. }}+\beta_{1}$ In $A G E+\beta_{2} E D U+\beta_{3}$ In INCOME $+\beta_{4} L O A N+\beta_{5} N E T+\beta_{6} C A R+$ $\beta_{7}$ MOBILE PHONE $+\varepsilon$

Where, $\beta_{0}$ is a constant, EXP $=$ domestic tourism expenditure, AGE $=$ household head's age, EDU= household head's educational level, INCOME = income of domestic tourism households for a year, LOAN = domestic tourism household loan, NET $=$ access of internet of household, CAR = household ownership of a car, MOBILE PHONE $=$ mobile phone ownership of the household head, $\beta_{i}(\theta)$ is the vector of parameters to be estimated for a given value of the distribution's quantile $\theta$ and $\varepsilon_{i}^{\theta}$ is the error term which is independently and identically distributed with symmetric distribution around zero. When the parameter $\theta$ is varied on the interval $(0,1)$, we can produce the entire conditional distribution of $\mathrm{y}$.

There is a difference in the level of spending from q05 to q95. In light of this, and in order to identify the differences between the visitors or tourists that are light spenders, medium spenders and heavy spenders, the study focuses on quantiles q05 t0 q95. In doing so, the study tries to explore the determinants of domestic tourism, mainly for domestic-same day visitors, domestic tourists and total domestic visitors.

Note: Total domestic visitors $=($ same-day visitors + overnight tourists $)$.

\section{Results}

\subsection{Empirical Results for Domestic Same-Day Visitor Travel Expenditure Determinants}

Table 4.16 reports on the empirical results for same-day visitor travel expenditure in Ghana. The quantile regression results reveal some interesting facts. The household head's age estimated coefficients for the $5^{\text {th }}, 10^{\text {th }}$ and $25^{\text {th }}$ quantiles are positively significant and $75^{\text {th }}, 90$ th and 95 th quantiles being negatively significant. This implies that age of household heads has positive effects on light spenders but negative effects on heavy same-day tourism expenditure households. The education coefficients of tourism expenditure are significant and negative at $5^{\text {th }}, 10^{\text {th }}, 25^{\text {th }}$ quantiles, indicating that same-day visitors with low education spend less on domestic tourism. 
For $75^{\text {th }}, 90^{\text {th }}$ and $95^{\text {th }}$ quantiles are significantly positive, demonstrating that education has positive effects on travel consumption for heavy same-day visitors.

Table 1: Empirical results for same-day visitor travel expenditure in Ghana

\begin{tabular}{|c|c|c|c|c|c|c|c|}
\hline \multicolumn{8}{|c|}{ Quantiles } \\
\hline Variable & 5 th & 10th & 25 th & 50th & 75 th & 90th & 95th \\
\hline \multirow[t]{2}{*}{ Constant } & 0.192 & 0.154 & $0.638^{* *}$ & $1.774 * *$ & $2.785^{* *}$ & $3.213^{* *}$ & $3.284 * *$ \\
\hline & $(0.137)$ & $(0.101)$ & $(0.051)$ & $(0.020)$ & $(0.051)$ & $(0.178)$ & $(0.203)$ \\
\hline \multirow[t]{2}{*}{ Age } & $-0.053 * *$ & $0.239 * *$ & $0.214^{* *}$ & 0.001 & $-0.096^{* *}$ & $-0.298 * *$ & $-0.162 *$ \\
\hline & $(0.035)$ & $(0.028)$ & $(0.016)$ & $(0.006)$ & $(0.016)$ & $(0.048)$ & $(0.047)$ \\
\hline \multirow[t]{2}{*}{ Education } & $-0.053 * *$ & $-0.042 * *$ & $-0.013 * *$ & -0.001 & $0.020 * *$ & $0.059 * *$ & $0.037 * *$ \\
\hline & $(0.014)$ & $(0.011)$ & $(0.005)$ & $(0.002)$ & $(0.049)$ & $(0.016)$ & $(0.018)$ \\
\hline \multirow[t]{2}{*}{ Income } & $0.032 * *$ & $0.047 * *$ & -0.002 & $0.006 * *$ & $0.017 * *$ & $0.087 * *$ & $0.088^{*}$ \\
\hline & $(0.016)$ & $(0.013)$ & $(0.007)$ & $(0.003)$ & $(0.007)$ & $(0.023)$ & $(0.026)$ \\
\hline \multirow[t]{2}{*}{ Loan } & $0.208 * *$ & $0.364 * *$ & $0.389 * * *$ & -0.018 & -0.409 & $-0.410 * *$ & $-0.233^{*}$ \\
\hline & $(0.109)$ & $(0.083)$ & $(0.037)$ & $(0.013)$ & $(0.036)$ & $(0.124)$ & $(0.137)$ \\
\hline \multirow[t]{2}{*}{ Internet } & -0.023 & -0.061 & -0.018 & 0.002 & 0.014 & -0.102 & -0.071 \\
\hline & $(0.086)$ & $(0.065)$ & $(0.031)$ & $(0.011)$ & $(0.030)$ & (0.099) & $(0.109)$ \\
\hline \multirow[t]{2}{*}{ Car } & -0.077 & -0.006 & -0.007 & 0.008 & 0.023 & 0.031 & $0.188^{*}$ \\
\hline & $(0.086)$ & $(0.064)$ & $(0.031)$ & $(0.011)$ & $(0.030)$ & $(0.099)$ & $(0.110)$ \\
\hline \multirow[t]{2}{*}{ M phone } & 0.028 & -0.042 & -0.004 & 0.010 & 0.020 & -0.012 & -0.051 \\
\hline & $(0.087)$ & $(0.066)$ & $(0.031)$ & $(0.001)$ & $(0.030)$ & $(0.099)$ & $(0.111)$ \\
\hline
\end{tabular}

Notes: $* * *, * *$ and $*$ are $10 \%, 5 \%$ and $1 \%$ are significant levels, and values in parenthesis are standard errors

The quantile regression estimates further indicate that the household income has positive effect on light, medium and heavy domestic same-day spenders. The regression estimates reveal that the effects of household income are relatively higher at the upper quartiles as compared to the lower quantiles. This suggests that domestic same-day travel is a normal good, and thus a rise in the income of same-day visitors will result in rise in same-day domestic tourism activities in Ghana.

With regard to household loan expense effect, the household loan coefficients on travel expenditure on same-day visitors are significantly positive at $5^{\text {th }} 10^{\text {th }}$ and 25 th quantiles, but negative at $90^{\text {th }}$ and $95^{\text {th }}$ quantiles. This indicates that household loan has positive greater influence on light domestic same-day spenders, however, domestic tourism expenditure is constrained by household loans for medium and heavy same-day tourism spenders.

For internet and mobile phone usage as proxies for information accessibility and car ownership as a proxy for transportation accessibility in the country, it is revealed from the table that internet and mobile phone variables have no relationship with the domestic tourism expenditure distribution, but car usage has positive effect on domestic tourism expenditure for heavy spenders. 


\subsection{Empirical Results for Domestic Overnight Tourists' Travel Expenditure Determinants}

Table 2 discusses the empirical results for domestic tourists' travel expenditure determinants in Ghana. The quantile regression estimates a positive and significant influence of the household head's age on the $5^{\text {th }}, 10^{\text {th }}$ and $25^{\text {th }}$ quantiles of the domestic travel expenditure distribution, and relatively highest at the $10^{\text {th }}$ quantile. These significantly positive age coefficients shows that age of household heads has greater positive effects on light domestic tourism spenders, but has negative effects on heavy domestic tourists' spenders.

The education coefficients on domestic tourists' travel expenditure distribution for different quantiles indicate that some are significant and negative, others significant and positive and some not significant at all. The observed negative sign of the quantile regression estimates of Education $\left(5^{\text {th }}, 10^{\text {th }}\right.$ and $\left.25^{\text {th }}\right)$ suggest that domestic tourists with lower education spend less on domestic tourism compared with tourists with higher education. On the other hand, education coefficients on domestic tourists' expenditure are higher at the $75^{\text {th }}$ and $90^{\text {th }}$ quantiles. This shows that education level has positive greater effects on domestic tourism consumption distribution for heavy spenders.

Table 2: Empirical results for domestic tourists' travel expenditure in Ghana

\begin{tabular}{|c|c|c|c|c|c|c|c|}
\hline \multirow{2}{*}{ Variable } & \multicolumn{4}{|c|}{ Quantiles } & \multirow[b]{2}{*}{75 th } & \multirow[b]{2}{*}{ 90th } & \multirow[b]{2}{*}{95 th } \\
\hline & 5 th & 10th & 25 th & 50th & & & \\
\hline \multirow[t]{2}{*}{ Constant } & -0.225 & 0.096 & $1.099 * *$ & $2.119 * *$ & $2.916 * *$ & $3.783 * *$ & $4.130 * *$ \\
\hline & $(0.104)$ & $(0.089)$ & $(0.079)$ & $(0.036)$ & $(0.096)$ & $(0.138)$ & $(0.191)$ \\
\hline \multirow[t]{2}{*}{ Age } & $0.079 * *$ & $0.173 * *$ & $0.033^{* *}$ & -0.004 & $-0.044 * *$ & $-0.053 * *$ & -0.031 \\
\hline & $(0.030)$ & $(0.026)$ & $(0.023)$ & $(0.011)$ & $(0.028)$ & $(0.040)$ & $(0.056)$ \\
\hline \multirow[t]{2}{*}{ Education } & -0.010 & -0.009 & $-0.005 * *$ & 0.002 & $0.039 * *$ & $0.062 * *$ & 0.028 \\
\hline & $(0.010)$ & $(0.009)$ & $(0.008)$ & $(0.004)$ & $(0.009)$ & $(0.013)$ & $(0.010)$ \\
\hline \multirow[t]{2}{*}{ Income } & $0.133 * *$ & $0.052 * *$ & $0.007 * *$ & $0.013 * *$ & $0.210 * *$ & $0.132 * *$ & $0.104 *$ \\
\hline & $(0.013)$ & $(0.011)$ & $(0.010)$ & $(0.005)$ & $(0.012)$ & $(0.017)$ & $(0 . \mathrm{O} 24)$ \\
\hline \multirow[t]{2}{*}{ Loan } & $0.499 * *$ & $0.640 * *$ & $0.566^{* * *}$ & $-0.317 * *$ & -0.219 & $-0.028 * *$ & $-0.225^{*}$ \\
\hline & $(0.070)$ & $(0.060)$ & $(0.054)$ & $(0.025)$ & $(0.065)$ & $(0.093)$ & $(0.129)$ \\
\hline \multirow[t]{2}{*}{ Internet } & 0.068 & 0.042 & -0.007 & $-0.017 *$ & 0.020 & 0.164 & $-0.065^{*}$ \\
\hline & $(0.059)$ & $(0.051)$ & $(0.046)$ & $(0.021)$ & $(0.055)$ & $(0.079)$ & (0.109) \\
\hline \multirow[t]{2}{*}{ Car } & -0.081 & -0.102 & -0.010 & -0.011 & -0.049 & -0.059 & $-0.027 *$ \\
\hline & $(0.059)$ & $(0.051)$ & $(0.046)$ & $(0.021)$ & $(0.055)$ & $(0.079)$ & $(0.109)$ \\
\hline \multirow[t]{2}{*}{ Mphone } & -0.046 & -0.062 & -0.016 & $-0.016^{*}$ & $-0.160 * *$ & $-0.267 * *$ & $-0.215^{*}$ \\
\hline & $(0.059)$ & $(0.051)$ & $(0.046)$ & $(0.021)$ & $(0.055)$ & $(0.079)$ & $(0.110)$ \\
\hline
\end{tabular}

Note: $* * *, * *$ and $*$ indicate $1 \%, 5 \%$ and $10 \%$ significant levels, respectively, and values in brackets or parenthesis are standard errors.

The household income coefficients on domestic tourism expenditure for different quantiles are positive from the lower $(0.05$ th) to the upper quartiles, showing that income level significantly influences domestic visitor travel expenditures. The household income coefficients is highest at $90^{\text {th }}$ quantile. The quantile regression estimates indicate further that the household income level significantly influences heavy household spenders than medium and light household spenders. This is in line with the study as the demand for Ghana's tourism goods and services is income elastic, it follows that an increase in income of domestic tourists would result in an increase in the demand for tourism goods and services in Ghana. The results are also in line with the previous studies (Hung 
et al, 2011) which confirm that domestic tourism is a normal good. It follows also the studies by Marrocu et al, 2015, which explains that tourist expenditure is driven by income.

With respect to household loan, the quantile regression estimated coefficients are positive at the lower quantiles, $(0.05),(0.10)$, and $(0.25)$, suggesting that household loans positively and significantly affect light spenders' travel consumption expenditure. However, the estimated coefficients are significantly negative at three different quantiles (i.e. $0.50,0.90$ and 0.95 ) of the domestic tourism expenditure distribution. This indicates that domestic tourism expenditure is constrained by household loans for medium and heavy spenders in Ghana. This is in contrast with a study by Hung et al, 2012, in Taiwan, where home loans are one of the major constraints of tourism spending for light spenders.

The study indicates that access to internet relates tourism expenditure negatively at q50 and q95 respectively. This implies that usage of internet is not an information source for heavy spenders for travel decisions and planning. Ownership of a car was estimated to be negatively related to domestic expenditures at the highest quantile (q95), suggesting that the use of car is not transport accessibility for domestic tourists spenders. Mobile phone usage is not an information source for medium and heavy spenders.

\subsection{Empirical Results for Domestic Visitors' Travel Expenditure Determinants}

Table 4 discusses the empirical results for domestic visitors' (domestic same-day and overnight visitors) travel expenditure determinants in Ghana. The household head's age coefficient are positive and significant at the $5^{\text {th }}$, $10^{\text {th }}$ and $25^{\text {th }}$ quantiles of the domestic travel expenditure distribution, and relatively highest at the $10^{\text {th }}$ quantile (0.218). These significantly positive age coefficients show that age of household heads have greater positive effects on domestic tourism expenditure for light spenders, but affect medium and heavy domestic tourism spenders negatively.

The education coefficients on domestic visitor's travel expenditure distribution for different quantiles indicate that $5^{\text {th }}$ and $10^{\text {th }}$ quantiles are significant and negative, $75^{\text {th }}, 90^{\text {th }}$ and $95^{\text {th }}$ quantiles are significant and positive but $25^{\text {th }}$ and $50^{\text {th }}$ are not significant. The observed negative sign of the quantile regression estimates of Education suggests that visitors with lower education spend less on domestic tourism and are light spenders. Education coefficients on domestic visitors' expenditure are highest at the $90^{\text {th }}$ quantile. This shows that educational level has greater effects on domestic tourism consumption distribution for heavy spenders.

The household income coefficients on domestic tourism expenditure for different quantiles are positive from the lower (0.05) to the upper quartiles, showing that income level significantly influences domestic visitor travel expenditures. The household income coefficients is highest at $90^{\text {th }}$ quantile which indicates further that the household income level significantly influences heavy domestic visitor spenders than light and medium domestic visitor spenders. This is in line with the study as the demand for the country's tourism goods and services is income elastic, it follows that an increase in income of domestic visitors would result in an increase in the demand for tourism goods and services.

With respect to household loan, the quantile regression estimated coefficients are positive at the lower quantiles, (0.05), (0.10), and (0.25) suggesting that household loans positively and significantly affect light domestic visitor spenders However, the estimated coefficients are significantly negative at three different quantiles (i.e. $0.5,0.9$ and 0.95 ) of the domestic tourism expenditure distribution. This indicates that domestic tourism expenditure is constrained by household loans for medium and heavy domestic tourism spenders in Ghana.

There were some important variables which the study thought would affect domestic visitors' consumption expenditure, including access to internet, ownership of a car and ownership of a mobile phone by households, but they proved otherwise. The results demonstrate that these variables have no relationships with the domestic tourism consumption expenditure distribution. This indicates that access to internet and ownership of a mobile phone are not information source for travel decisions and planning, while usage of a car for domestic tourism purposes is not popular by domestic visitors in Ghana. 
Table 4: Empirical results for domestic visitors' travel expenditure in Ghana

\begin{tabular}{|c|c|c|c|c|c|c|c|}
\hline \multicolumn{8}{|c|}{ Quantiles } \\
\hline Variable & 5 th & 10th & 25 th & 50th & 75 th & 90th & 95 th \\
\hline \multirow[t]{2}{*}{ Constant } & 0.020 & 0.135 & $0.784 * *$ & $1.850 * *$ & $2.718 * *$ & $3.218 * *$ & $3.530 * *$ \\
\hline & $(0.087)$ & $(0.094)$ & $(0.059)$ & $(0.027)$ & $(0.086)$ & $(0.158)$ & $(0.121)$ \\
\hline \multirow[t]{2}{*}{ Age } & $0.141 * *$ & $0.218 * *$ & $0.119 * *$ & -0.001 & $-0.091 * *$ & 0.056 & -0.071 \\
\hline & $(0.024)$ & $(0.026)$ & $(0.016)$ & $(0.007)$ & $(0.023)$ & $(0.043)$ & $(0.033)$ \\
\hline \multirow[t]{2}{*}{ Education } & $-0.044 * *$ & $-0.038 * *$ & -0.008 & 0.001 & $0.031 * *$ & $0.049 * *$ & $0.038 * * *$ \\
\hline & $(0.008)$ & $(0.009)$ & $(0.006)$ & $(0.003)$ & $(0.008)$ & $(0.015)$ & $(0.012)$ \\
\hline \multirow[t]{2}{*}{ Income } & $0.100 * *$ & $0.066 * *$ & $0.001 *$ & $0.006 * *$ & $0.118 * *$ & $0.144 * *$ & $0.099 * *$ \\
\hline & $(0.010)$ & $(0.011)$ & $(0.007)$ & $(0.003)$ & $(0.010)$ & $(0.018)$ & (0.014) \\
\hline \multirow[t]{2}{*}{ Loan } & $0.323 * *$ & $0.466^{* *}$ & $0.589 * * *$ & $-0.067 * *$ & -0.822 & $-0.517 * *$ & -0.239 \\
\hline & $(0.057)$ & $(0.062)$ & $(0.039)$ & $(0.018)$ & $(0.058)$ & $(0.104)$ & $(0.080)$ \\
\hline \multirow[t]{2}{*}{ Internet } & -0.029 & -0.004 & -0.004 & -0.005 & 0.012 & 0.121 & -0.08 \\
\hline & $(0.048)$ & $(0.052)$ & $(0.033)$ & $(0.015)$ & $(0.048)$ & $(0.088)$ & $(0.067)$ \\
\hline \multirow[t]{2}{*}{ Car } & $-0.115^{*}$ & -0.055 & -0.009 & 0.002 & -0.009 & -0.065 & 0.025 \\
\hline & $(0.048)$ & $(0.052)$ & $(0.033)$ & $(0.015)$ & $(0.048)$ & $(0.087)$ & $(0.066)$ \\
\hline \multirow[t]{2}{*}{ Mphone } & $-0.088 *$ & -0.046 & -0.001 & -0.001 & -0.056 & -0.121 & -0.147 \\
\hline & $(0.048)$ & $(0.052)$ & $(0.033)$ & $(0.015)$ & $(0.048)$ & $(0.088)$ & $(0.067)$ \\
\hline
\end{tabular}

Notes: $* * *, * *$ and $*$ are $10 \%, 5 \%$ and $1 \%$ are significant levels, and values in parenthesis are standard errors

Hence, unlike in the advanced countries where there is a rise in car ownership, mobile phone and internet accessibility, and that internet access is the main information source for travel decisions and planning, in Ghana these devices are not used for information source for travel decisions and planning in terms of domestic tourism.

\section{Discussion}

The quantile regression estimates show that the household head's age has positive effects on the domestic visitors' travel expenditure for light spenders and negatively affects heavy spenders for the two categories of domestic visitors, same-day visitors and overnight tourists. The observed negative sign of quantiles $75^{\text {th }}$ and $90^{\text {th }}$ of both same-day visitors and overnight tourists suggest that domestic tourism expenditure decreases as household head's age increases. The results show that visitors with low education level spend less on domestic tourism while those who are well educated are prepared to spend more.

The quantile regression estimates further indicate that the household income level significantly influences domestic travel expenditure. This is because the quantiles are positive from lowest to the highest. This suggests that the household income level significantly affects light, medium and heavy household spenders. This indicates that higher tourism expenditure households have higher income elasticity of demand. The higher the income the more Ghana's visitors will spend on tourism.

The household loans positively and significantly affect light spenders, however, by the study, it is interesting to note that domestic tourism expenditure is constrained by household loans for medium and heavy spenders. The result is in contrast with Hung et al (2012), where according to the paper, home loans are major constraints of tourism spending for light spenders. In Ghana, household loans are major constraints of domestic tourism spending for medium and heavy spenders. 
The results demonstrate that access to internet and ownership of mobile phones in Ghana are not determinants of domestic overnight travel expenditure and are not information source. This is because these variables have no relationship with the domestic tourism expenditure. This could be due to the fact that majority of domestic visitors are illiterates, and some are not conversant with information communication technology (ICT), and hence cannot use computer as the main source for travel decisions and planning for domestic tourism activities. With respect to car ownership, the results demonstrate that it does not relate domestic tourism expenditure. This indicates that independent domestic tourism travel by car is not popular in Ghana. Finally, the results show that internet access, ownership of a car and ownership of a mobile phone do not affect domestic visitors' consumption expenditure in Ghana which is in contrast with Hung et al, 2011, where in their case, there was a rise in internet accessibility and advertisement as well as an increase in car ownership which are key determinants of travel industry operations in Taiwan.

\section{Conclusions}

The study is the first of its kind to examine the determinants of domestic tourism consumption using quantile regression approach in Ghana and it identifies the main determinants (income of households, household loan, age of household head and educational level of household head) and their impacts on individual spending for domestic visitors. The research finds that relatively older and well educated households with higher income levels are prepared to spend more on domestic tourism in Ghana. The findings of the study offer in-depth knowledge on the spending behaviour of domestic visitors' participation in Ghana and the information provided offers tourism operators, suppliers, policy makers and governments to plan event strategies which focus on definite segments of domestic visitors with respect to how they spend.

To study the determinants of domestic tourism expenditure provides the impetus to estimate the sociodemographic impact of factors and to take the recognition of useful information for travel decision making and planning in the tourism industry. Generally, the study provides useful information for decision-making in the tourism industry for policy makers, tourism practitioners and suppliers of their first interest in this kind of study to utilise it to develop strategies of tourism activities in Ghana and beyond. The main contribution of this study is that it tests the response of spending behaviour of domestic visitors in Ghana using determinants directly in relation to domestic tourism expenditure which have been seldom taken into consideration.

For internet and mobile phone usage, the study finds out that these do not affect domestic tourism expenditure, and hence internet facility centres should be dotted across the country for use by the citizenry. With respect to household loan, the findings disclose that in Ghana, household loans are one of the major constraints of domestic tourism spending, for medium and heavy spenders, but positively affect light domestic tourism expenditure households, hence, well-developed and comprehensive loan packages should be made available to potential light domestic visitor consumers.

Independent domestic tourism travel is not popular by cars in Ghana, according to the study, and it thus behoves on government and private sector operators like Ghana Private Road Transport Union (GPRTU) to encourage the influx of affordable saloon cars into the country, as this will pave way for more people to have access to saloon cars to increase the urge for domestic tourism participation.

It is a fact that there is less telecommunication equipment in Ghana, and thus an increase in telecommunication equipment and improvements in communication networks in every part of the country will assist the rural and urban inhabitants to have access to information on domestic tourism.

The analysis finds that educational level of household heads has significant effects on domestic tourism expenditure, therefore tourism studies should be made part of the first and second cycle schools curricula to rekindle the enthusiasm of students to have interest and participate in domestic tourism activities. Prices of mobile phones in Ghana should be made affordable by government by decreasing the taxes on them to enable the citizenry to use them. 


\section{References}

Allen, D. E. et al (2009), “Quantile Regression: Its Application in Investment Analysis”. The Finsia Journal of Applied Finance, Issue 4

Buchinsky, Moshe (1998), “Recent Advances in Quantile Regression Models: A Practical Guideline for Empirical Research', Journal of Human Resources Vol.33 No. 1 (Winter 1998) pp.88-126

Fitzenberger, B. \& Kunge, A. (2005), "Vocational Training and Gender: Wages and Occupational Mobility among Young Workers. Journal.

Fitzenberger, B. (2012), “Quantile Regression. Discussion.’’ Paper No.05-65.

Frechtling, D. C. (2001), “Forecasting Tourism Demand: Methods and Strategies”’. Oxford, U.K

Frechtling, D. C. (2006), “An Assessment of Visitor Expenditure Methods and Models. Journal of Travel Research, Volume XX pp 1-10

Hamal, K. (1996), “Tourism and the Economy: Understanding the Economics of Tourism. Posted 2004 Categories: Hawaii’s economy, UHERO Working Papers

Hamal, K. (1998), “Australian Outbound Travel Demand: Long - Haul Versus Short-Haul”. Bureau of Tourism Research, Conference Paper

Holton Wilson,J. and Barry Keating (1994), “Business forecasting”. McGraw-Hill Co. Inc. USA

Hung, W. T., Shang, J. K. and Wang, F. C. (2011), "Understanding Determinants of Domestic Travel Consumption". International Journal of Advances in Management Sciences, Volume: 1-1.

Hung, W. T., Shang, J. K. and Wang, F. C. (2012), "Another Look at the Determinants of Tourism Expenditure'’. Annals of Tourism Research, 2012, Vol 39, No. 1, pp 495 - 498

Ichiro, T., Nomura, K. \& Takafumi, K. (2006), “Non-Parametric Quantile Estimation”. Journal of Machine Learning

Koenker, R. (2015), “Quantile Regression in R: A Vignette’’ Journal

Koenker and Basset (1978), “Quantile Regression. Econometrica’, Vol. 46, No. 1.pp 33-50.

Liew Chei Siang \& Zulridah Mohd Noor (2015), “The Impact of Training on the Conditional Wage Distribution in Selected Service Sub-sectors in Malaysia', Journal Ekonomi Malaysia 49(1)2015 37-48

Marrocu, E., Paci, R. and Zara, A. (2015), “Micro-Economic Determinants of Tourist Expenditure: A Quantile Regression Approach', Tourism Management Journal. Homepage

Pin, T. Ng and Alan A. Lew (2009). “Quantile regression analysis of visitor spending: an example of Mainland Chinese tourists in Hong Kong’’. Working Paper Series - 09 - 06.

Salgado-Barandela, J., Baraja, A. \& Sanchez-Fernandez, P.(2018), “Determinants of the Spending of Sporting Tourists: The Case of Attendees at Professional Basketball'. Journal of European research on management and business Economics 24 (2018) pp 168 - 176

Sotiriadis, M. and Varvaressos, S (2014). “A Strategic Analysis of Greek Tourism: Competitive Position, Issues and Lessons" .International Journal of Tourism Hospitality and Leisure, Vol 4(2) 